\title{
First rare-earth phosphate aerogel: sol-gel synthesis of monolithic ceric hydrogen
}

\section{phosphate aerogel}

Yorov K.E. ${ }^{1}$, Shekunova T.O. ${ }^{1,2}$, Baranchikov A.E. ${ }^{1,2}$, Kopitsa G.P. ${ }^{3,4}$, Almásy L. ${ }^{5}$, Skogareva L.S. ${ }^{2}$, Kozik V.V. ${ }^{6}$, Malkova A.N. ${ }^{7}$, Lermontov S.A. ${ }^{7}$, Ivanov V.K. ${ }^{2,8 *}$

${ }^{1}$ Lomonosov Moscow State University

${ }^{2}$ Kurnakov Institute of General and Inorganic Chemistry of the Russian Academy of Sciences

${ }^{3}$ Petersburg Nuclear Physics Institute of National Research Centre "Kurchatov Institute"

${ }^{4}$ Grebenshchikov Institute of Silicate Chemistry of the Russian Academy of Sciences

${ }^{5}$ Institute for Solid State Physics and Optics, Wigner Research Centre for Physics, Hungarian Academy of Sciences

${ }^{6}$ National Research Tomsk State University

${ }^{7}$ Institute of Physiologically Active Compounds of the Russian Academy of Sciences

${ }^{8}$ Lomonosov Moscow State University of Fine Chemical Technologies

\section{Annotation}

Since the late 1960s, ceric hydrogen phosphates have attracted the attention of scientists due to remarkable ion exchange, sorption, proton-conduction and catalytic properties. In this work, through the application of various solvents, we, for the first time, have obtained monolithic aerogels based on ceric hydrogen phosphates with high porosity ( 99\%) and extremely low density $\left(\sim 10 \mu \mathrm{g} / \mathrm{cm}^{3}\right)$. The composition and structure of aerogels were thoroughly studied with XRD, TEM, SEM, XPS, low temperature nitrogen adsorption methods, TGA/DSC, FTIR and SANS. The aerogels were found to belong to the fibrous macroporous aerogels family.

\section{Introduction}

Aerogels, being highly porous materials with low density and high specific surface area, are gels in which the liquid phase is completely replaced by a gaseous phase [1]. Aerogels are typically used as catalysts, sensors, ion-exchange materials, and as heat and sound insulators [2]. They can be produced from a number of simple substances, both inorganic and organic compounds; hybrid organic-inorganic aerogels are also known [3-17]. 
The most studied $\mathrm{SiO}_{2}$-based aerogels, obtained by hydrolysis of silicon alkoxides, with subsequent supercritical drying, consist of isotropic $\mathrm{SiO}_{2}$ nanoparticles (0D) forming a spatial network [18]. Recently, a significant number of papers have also been published on the production of aerogels containing anisotropic 1D and 2D building blocks, including carbon nanotubes and graphene [19-22]. Special attention has been paid to monolithic materials having a similar architecture, but containing not only micropores $(<2 \mathrm{~nm})$ and mesopores $(2-50 \mathrm{~nm})$, but also macropores, since they have a highly accessible surface, which is guaranteed by macroporosity. In addition to the high permeability of such materials, which is important for their application as catalysts and sensors, they can be easily recovered for repetitive use [23].

One of the most challenging tasks in the design of new multifunctional materials is the production of aerogels from orthophosphates of transition and rare-earth elements. Such materials could attract a great deal of interest, due to their extended applications in various possible applications, such as ion-exchange for water purification, catalysts, proton conductors, etc. At the same time, the data on the synthesis of such materials is extremely scarce. Thus, methods are reported for the synthesis of aerogels of the compositions $\mathrm{Ti}_{3}\left(\mathrm{PO}_{4}\right)_{4} / \mathrm{Si}_{3}\left(\mathrm{PO}_{4}\right)_{4}$, $\mathrm{AlPO}_{4} / \mathrm{Si}_{3}\left(\mathrm{PO}_{4}\right)_{4}, \quad \mathrm{Si}_{3}\left(\mathrm{PO}_{4}\right)_{4}, \quad \mathrm{Zn}_{3}\left(\mathrm{PO}_{4}\right)_{2}, \quad \mathrm{Zn}_{3}\left(\mathrm{PO}_{4}\right)_{2} / \mathrm{Si}_{3}\left(\mathrm{PO}_{4}\right)_{4}, \quad \mathrm{AlPO}_{4}, \quad \mathrm{Ti}_{3}\left(\mathrm{PO}_{4}\right)_{4} \quad$ и $\mathrm{Zr}_{3}\left(\mathrm{PO}_{4}\right)_{4} / \mathrm{Si}_{3}\left(\mathrm{PO}_{4}\right)_{4}$ [24]. Zhu et al. [23] described the synthesis of a monolithic aerogel based on zirconium phosphate, which can be used for the purification of water as a heavy metals sorbent. Studies concerning the preparation of surface-modified, phosphate-containing oxide aerogels have been also reported [25-28]. In particular, Boyse et al. [25] obtained $\mathrm{Nb}_{2} \mathrm{O}_{5}$-based aerogels containing 5 or $10 \mathrm{~mol} \%$ of niobium phosphate, which showed a high level of catalytic activity in the reaction of butene-1 isomerisation.

The synthesis of rare-earth phosphate aerogels has not been reported, to date, although they may be of considerable interest, due to a number of valuable properties, including sorption [29], ion exchange [30], proton-conduction [31] and catalytic activities [32], which are typical, in particular, of cerium (IV) hydroorthophosphates. Despite the long history of cerium phosphates $[33,34]$, cerium (III) orthophosphates of monazite or rhabdophane structures [35] remain the most investigated, whereas cerium (IV) orthophosphates have been studied to a much lesser degree. Only recently, crystalline structures of two acidic phosphates of cerium (IV), $\mathrm{Ce}\left(\mathrm{PO}_{4}\right)\left(\mathrm{HPO}_{4}\right)_{0.5}\left(\mathrm{H}_{2} \mathrm{O}\right)_{0.5}$ and $\mathrm{Ce}\left(\mathrm{PO}_{4}\right)_{1.5}\left(\mathrm{H}_{2} \mathrm{O}\right)\left(\mathrm{H}_{3} \mathrm{O}\right)_{0.5}\left(\mathrm{H}_{2} \mathrm{O}\right)_{0.5}$ were solved by Nazaraly et al. [36-38].

In the present study, we made the first attempt to obtain aerogels based on ceric hydrogen phosphates, to yield materials possessing higher porosity, and better mechanical strength and chemical stability, in comparison to wet gels. Guidance for our attempt was the fact that wet gels of monolithic ceric hydrogen phosphates are easily formed by mixing cerium-containing 
hydrogen phosphate solutions with water [39]. It was reasonable to assume that, under certain conditions, these gels could be dried supercritically, resulting in monolithic aerogel materials.

\section{Materials and methods}

The following materials were used, as received and without further purification: $\mathrm{Ce}\left(\mathrm{NO}_{3}\right)_{3} \cdot 6 \mathrm{H}_{2} \mathrm{O}$ (99\%, Aldrich \#238538), orthophosphoric acid (85 wt.\% aq., analytical grade, Khimmed Russia), aqueous ammonia (25 wt.\%, extra-pure grade, Khimmed Russia), isopropanol (extra-pure grade, Khimmed Russia), acetonitrile (analytical grade, Khimmed Russia), methyl tert-butyl ether (Acros, 99\%), distilled or deionised (18 M $\Omega$ ) water.

To obtain cerium (IV) orthophosphate gels, we used a technique developed in our group recently [40]. A typical procedure for the synthesis of a monolithic wet gel involves the dissolution of $0.020 \mathrm{~g}$ of $\mathrm{CeO}_{2}$ powder (prepared according to [41]) in $1 \mathrm{ml} \mathrm{of} \mathrm{H}_{3} \mathrm{PO}_{4}(85 \mathrm{wt} . \%$, $\rho=1.689 \mathrm{~g} / \mathrm{cm}^{3}$ ) under constant stirring at $100^{\circ} \mathrm{C}$. After the $\mathrm{CeO}_{2}$ was completely dissolved and the solution showed no Tyndall effect, the solution was cooled to room temperature, (the solution is hereafter referred to as $\mathbf{s C e P}$, molar ratio Ce:P is equal to 1:140), and $4 \mathrm{ml}$ of distilled water or $4 \mathrm{ml}$ of methyl tert-butyl ether (MTBE) was added. As a result, a gel was formed, which was aged for 10 days, then the solvent was replaced by keeping the gel in acetonitrile for one week, with a daily solvent change. The samples were dried under supercritical conditions, to obtain the aerogels. As solvents for the supercritical drying, we used carbon dioxide and MTBE. A glass tube containing wet gel under an MTBE layer $(14-16 \mathrm{~mL})$ was placed in an autoclave (V $=38 \mathrm{~mL}$ ). The autoclave was mounted in a furnace, heated at a rate of $100^{\circ} \mathrm{C} / \mathrm{h}$ to $235-245^{\circ} \mathrm{C}$ (6.0-7.0 $\mathrm{MPa}$ ) and held at that temperature for 10-15 min. Next, the pressure in the heated autoclave was gradually lowered to atmospheric pressure and the autoclave was evacuated for 30 $\min (30-40 \mathrm{kPa})$, cooled and opened.

Supercritical drying in $\mathrm{CO}_{2}$ was carried out in a system that comprised a Supercritical 24 high pressure pump for $\mathrm{CO}_{2}$ (SSI, USA), a $50 \mathrm{~mL}$ steel reactor and a BPR back pressure regulator (Goregulator, Waters, USA). The sample was washed with liquid $\mathrm{CO}_{2}$ for $2 \mathrm{~h}$ at a temperature of $20^{\circ} \mathrm{C}$ and pressure of $15 \mathrm{MPa}$. The temperature in the reactor was then raised to $50^{\circ} \mathrm{C}$ and the sample was washed with supercritical $\mathrm{CO}_{2}(15 \mathrm{MPa})$ for $2-2.5 \mathrm{~h}$. Next, the pressure in the heated autoclave was gradually (30-40 $\mathrm{min})$ lowered to atmospheric pressure and the autoclave was cooled and opened [42].

As a reference sample, a xerogel was used, the synthesis of which included mixing the cerium-containing phosphoric acid solution and water, purifying the resulting gel by dialysis against deionised water and drying the purified gel at $60^{\circ} \mathrm{C}$ under atmospheric pressure. 
X-ray powder diffraction patterns were recorded with a Bruker D8 Advance diffractometer using $\mathrm{CuK}_{\alpha}$ radiation in the $2 \theta$ range $3-120^{\circ}$ at a $2 \theta$ step of $0.02^{\circ}$ and a counting time of $0.3 \mathrm{~s}$ per step.

The microstructure of the samples was studied by means of transmission electron microscopy (TEM) with a Leo912 AB Omega analytical transmission electron microscope. TEM images were taken at an accelerating voltage of $100 \mathrm{kV}$ in the bright-field mode.

The microstructure (scanning electron microscopy, SEM) and the chemical composition (energy dispersive X-ray analysis, EDX) of the samples were analysed on a Carl Zeiss NVision 40 high-resolution scanning electron microscope equipped with an Oxford Instruments X-MAX $\left(80 \mathrm{~mm}^{2}\right)$ detector, operating at an accelerating voltage of 1-20 kV. SEM images were taken with an Everhart-Thornley detector (SE2) at $1 \mathrm{kV}$ accelerating voltage.

The investigation of the chemical composition of the surface layers of ceric hydrogen phosphate materials was conducted by X-ray photoelectron spectroscopy (XPS) on a SPECS Xray photoelectron spectrometer with a PHOIBOS-150 energy analyser in fixed analyser transmission mode $(15 \mathrm{eV})$, using $\mathrm{MgK} \alpha$ radiation $(h v=1253.6 \mathrm{eV})$. Experimental data processing was performed with the CasaXPS software package.

Specific surface areas of powders were determined by low temperature nitrogen adsorption on an ATX-6 analyser (Katakon, Russia), using the 5-point Brunauer-Emmett-Teller (BET) model at partial pressures in the range $0.05-0.25$. Pore size distribution was assessed by the Barrett-Joyner-Halenda (BJH) method, using adsorption isotherms at partial pressures in the range $0.4-0.97$.

Thermal analysis was performed on a TGA/DSC/DTA SDT Q-600 analyser (TA Instruments), upon linear heating to $1,000^{\circ} \mathrm{C}$ (heating rate of $10^{\circ} \mathrm{C} / \mathrm{min}$ ) in a $250 \mathrm{ml} / \mathrm{min}$ airflow.

The FTIR spectra of the samples were recorded on a Perkin Elmer Spectrum One spectrometer, in a range of $450-4000 \mathrm{~cm}^{-1}$, in attenuated total reflectance mode.

The SANS experiment was performed using the "Yellow Submarine" instrument of the $\mathrm{BNC}$ research reactor, in Budapest (Hungary), which operates in near point geometry. The use of two neutron wavelengths ( $\lambda=4.9$ and $9.4 \AA, \Delta \lambda / \lambda=18 \%$ ) and two sample-to-detector distances $(1.57$ and $5.5 \mathrm{~m})$ provided measurements in the momentum transfer range of $6 \cdot 10^{-3}<q<0.3 \AA^{-1}$. The BerSANS software [43] was used for data pre-processing.

\section{Results and discussion}

Directly upon addition of distilled water to the $\mathrm{sCeP}$ solution, the formation of a solid phase (gel) was observed. A stable and cohesive gel was formed at the ratios $V_{\mathrm{sCeP}}: V_{\text {water }}=1: 2-$ 
1:6 (see Table 1). When a smaller volume of water was added, the gel was not formed; with the ratio of $V_{\mathrm{sCeP}}: V_{\text {water }}>1: 8$, the resulting gel broke down after 1 week of ageing.

Table 1. Formation of ceric phosphate hydrogels at different volume ratios of reactants

\begin{tabular}{|c|c|c|c|c|c|}
\hline Entry & $\begin{array}{c}\text { Volume of } \\
\text { sCeP solution, } \\
\text { (ml) }\end{array}$ & $\begin{array}{c}\text { Water } \\
\text { volume, } \\
(\mathrm{ml})\end{array}$ & $\begin{array}{c}\text { Molar } \\
\text { ratio } \\
\text { Ce: } \mathrm{H}_{2} \mathrm{O}\end{array}$ & Formation of gel & Ageing for 7 days \\
\hline V1 & 1 & 1 & $1: 530$ & No & - \\
\hline $\mathrm{V} 2$ & 1 & 2 & $1: 1060$ & Yes & $\begin{array}{l}\text { Gel remains } \\
\text { monolithic }\end{array}$ \\
\hline V4 & 1 & 4 & $1: 2120$ & Yes & $\begin{array}{l}\text { Gel remains } \\
\text { monolithic }\end{array}$ \\
\hline V6 & 1 & 6 & $1: 3180$ & Yes & $\begin{array}{l}\text { Gel remains } \\
\text { monolithic }\end{array}$ \\
\hline V8 & 1 & 8 & $1: 4250$ & Yes & Gel breaks down \\
\hline V10 & 1 & 10 & $1: 5300$ & Yes & Gel breaks down \\
\hline
\end{tabular}

Interestingly, the formation of the gel was observed not only when the cerium-containing phosphate solution interacted with distilled water, but also when sCeP was mixed with nonaqueous solutions, including protic or aprotic solvents (methanol, ethanol, isopropanol, ethylene glycol, acetone, methyl tert-butyl ether and tetrahydrofuran). Table 2 contains the results of the corresponding experiments. The reason for the observed effect is still unclear, and, for its clarification, data are required on the ceric coordination chemistry in non-aqueous orthophosphoric acid solutions, which are rather scarce. It should be noted that the obtained gels did not always remain monolithic upon ageing (Table 2, experiments S2, S5, S9, S10). The breakdown of gels in these cases was probably associated with the reduction of $\mathrm{Ce}^{+4}$ ions to $\mathrm{Ce}^{+3}$, due to the oxidation of the corresponding solvent under acidic $\left(\mathrm{H}_{3} \mathrm{PO}_{4}\right)$ conditions. To determine which of the obtained gels remain monolithic after solvent replacement, the obtained samples were further dialysed against deionised water (see Table 2). The results of this experiment revealed that only in entries S1 and S8 (see Table 2) did the samples remain monolithic. 
Table 2. The effect of solvent nature on the formation of Ce (IV) phosphate gel

\begin{tabular}{|c|c|c|c|c|}
\hline Entry & Solvent & Formation of gel & $\begin{array}{l}\text { After aging } \\
\text { (12 days), when } \\
\text { transferred to a test } \\
\text { tube with distilled } \\
\text { water }\end{array}$ & $\begin{array}{l}\text { After replacing the } \\
\text { solvent with distilled } \\
\text { water }\end{array}$ \\
\hline S1 & Water & Yes & $\begin{array}{l}\text { Gel remains } \\
\text { monolithic }\end{array}$ & $\begin{array}{l}\text { Gel remains } \\
\text { monolithic }\end{array}$ \\
\hline S2 & Methanol & Yes & Gel disintegrates & - \\
\hline S3 & Ethanol & Yes & $\begin{array}{l}\text { Gel remains } \\
\text { monolithic }\end{array}$ & Gel disintegrates \\
\hline S4 & Isopropanol & Yes & $\begin{array}{l}\text { Gel remains } \\
\text { monolithic }\end{array}$ & Gel disintegrates \\
\hline S5 & Acetone & Yes & Gel disintegrates & - \\
\hline S6 & Acetonitrile & No & - & - \\
\hline S7 & Diethyl ether & No & - & - \\
\hline S8 & MTBE & Yes & $\begin{array}{l}\text { Gel remains } \\
\text { monolithic }\end{array}$ & $\begin{array}{l}\text { Gel remains } \\
\text { monolithic }\end{array}$ \\
\hline S9 & Tetrahydrofuran & Yes & Gel disintegrates & - \\
\hline S10 & Ethylene glycol & Yes & Gel disintegrates & - \\
\hline S11 & Hexane & No & - & - \\
\hline
\end{tabular}

Hence, in the following, for the synthesis of aerogels, we used wet gels obtained by adding the distilled water or MTBE to a solution of cerium-containing phosphoric acid in a volume ratio of 4:1 (see Table 1, Table 2, experiments S1, S8). The selected gels, upon replacement of the solvent with acetonitrile, were dried under supercritical conditions in $\mathrm{CO}_{2}$ and in MTBE (Fig. 1). For the sake of clarity, the samples synthesised in this way are hereafter named as follows:

\begin{tabular}{lcccc}
\hline \multicolumn{1}{c}{ Notation } & CePH & CePM & CePMTB & CePx* \\
\hline $\begin{array}{l}\text { Solvent used for } \\
\text { wet-gel synthesis }\end{array}$ & $\mathrm{H}_{2} \mathrm{O}$ & MTBE & MTBE & $\mathrm{H}_{2} \mathrm{O}$ \\
$\begin{array}{l}\text { Solvent used for } \\
\text { supercritical drying }\end{array}$ & $\mathrm{CO}_{2}$ & $\mathrm{CO}_{2}$ & MTBE & ambient pressure drying in \\
\hline
\end{tabular}

* xerogel obtained as a reference sample according to the reported synthetic procedure [40] 


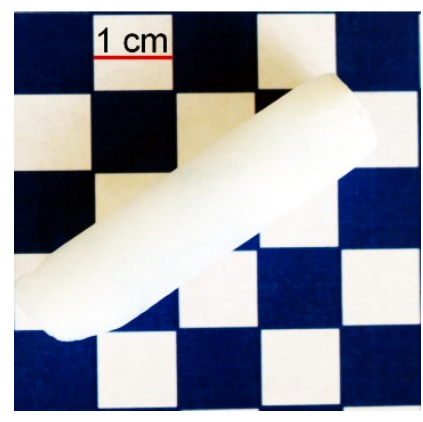

(a)

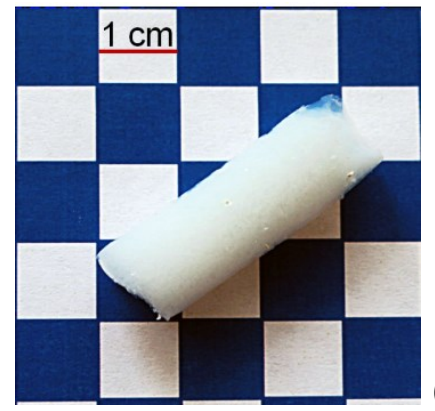

(b)
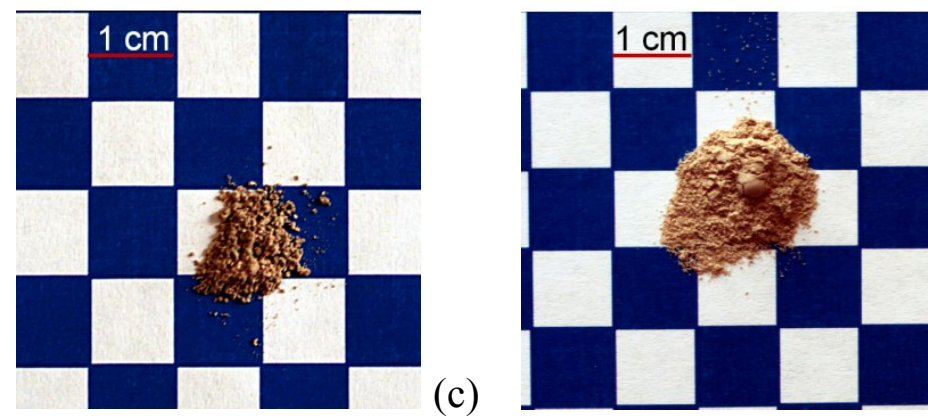

(d)

Fig. 1. The appearance of the obtained samples: (a) - CePH, (b) - CePM, (c) - CePMTB, (d) CePx.

It was demonstrated that supercritical drying in $\mathrm{CO}_{2}$ leads to the successful production of monolithic aerogels (Fig. 1a, b). Their mechanical strength is quite high for common handling, but somewhat lower than that of silica aerogels synthesized by common procedures. Note that monolithic aerogel samples are visually white, whereas powdered samples prepared from the same hydrogels are coloured (Fig. 1). The diffuse UV-vis reflectance spectra (Fig. S1) of colourless $\mathrm{CePH}$ and coloured CePx samples are nearly identical, indicating that the aerogels' colourlessness is probably due to their low density and multiple scattering of ambient light by the solid-gas interfaces. Actually, the geometrical density of monolithic aerogels (CePH and CePM) amounts to $\sim 0.01 \mathrm{~g} / \mathrm{cm}^{3}$. The porosity of the obtained aerogels was estimated using the formula [44]:

$$
P=\left(1-\frac{\rho_{1}}{\rho_{2}}\right) \cdot 100 \%,
$$

where $\rho_{1}$ is the aerogel density and $\rho_{2}$ is the skeletal density. The skeletal density of aerogel samples, as measured using a Pycnomatic ATC helium pycnometer, was equal to $2.98 \pm 0.04$ $\mathrm{g} / \mathrm{cm}^{-3}$. The calculated porosity of the monolithic aerogels was $\sim 99 \%$.

According to X-ray diffraction analysis of aerogels obtained by drying in supercritical $\mathrm{CO}_{2}$ and xerogel, CePx are mostly X-ray amorphous (Fig. 2 a, b, c). 


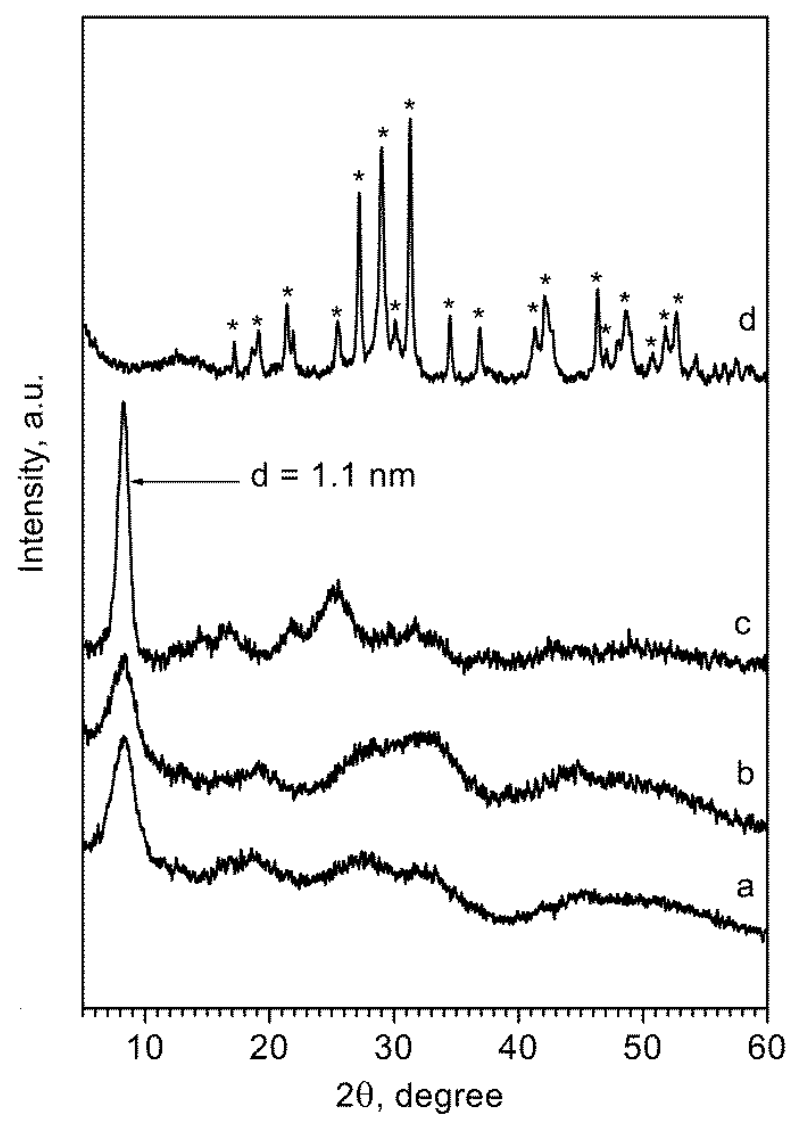

Fig. 2. X-ray diffraction patterns of ceric hydrogen phosphate aerogels and xerogels: (a) CePx, (b) $\mathrm{CePH}$, (c) CePM, (d) CePMTB. The peaks corresponding to the monazite phase are indicated with an asterisk.

In the diffractograms of these samples, at $2 \theta \sim 8^{\circ}$, one can observe a pronounced broadened maximum, which may indicate the existence of short-range order in ceriumcontaining hydrogen orthophosphate gels with a characteristic distance of $\sim 1.1 \mathrm{~nm}$. The presence of this peak for cerium-phosphate gels has also been reported previously [40,45]. Hayashi et al. [46] presumed that the presence of this peak is due to the layered structure of the gels allowing them to be intercalated with e.g. oleylamine [46]. The diffractogram for the CePM aerogel (Fig. 2c) is almost the same as the diffractogram for the Ce (IV) hydrogen phosphate of $\mathrm{Ce}\left(\mathrm{HPO}_{4}\right)_{2} \cdot 3.5 \mathrm{H}_{2} \mathrm{O}$ composition, which was obtained by Hayashi et al. by a procedure involving the preparation of $\mathrm{Ce}\left(\mathrm{SO}_{4}\right)_{2} \cdot 4 \mathrm{H}_{2} \mathrm{O}$ solution in $0.5 \mathrm{M} \mathrm{H}_{2} \mathrm{SO}_{4}$, followed by its addition to a solution of $6 \mathrm{M} \mathrm{H}_{3} \mathrm{PO}_{4}\left(95^{\circ} \mathrm{C}\right)$, followed by digestion at $95^{\circ} \mathrm{C}[46]$. 
The CePMTB sample (Fig. 2 d) was a single-phase monazite $\left(\mathrm{CePO}_{4}\right.$, PDF2 №32-199). The formation of trivalent cerium orthophosphate seems to be the result of the oxidation of methyl tert-butyl ether during synthesis at high temperature (about $250^{\circ} \mathrm{C}$ ), (probably with the formation of tert-butyl formate and tert-butyl alcohol), with simultaneous reduction of Ce (IV) [47]. As supercritical drying in the MTBE medium failed to yield a monolithic aerogel, further detailed studies of the CePMTB sample were not conducted.

Fig. 3 shows the results of thermal analysis of $\mathrm{CePx}, \mathrm{CePM}$ and $\mathrm{CePH}$ samples. In general, both xerogel (CePx) and aerogels ( $\mathrm{CePH}$ and $\mathrm{CePM})$ exhibited similar behaviour upon heating, and their thermal decomposition was of a multistage nature. In the region of relatively low temperatures (up to $\sim 200^{\circ} \mathrm{C}$ ), physically bound molecules of water, acetonitrile and others were removed. At temperatures up to $\sim 500^{\circ} \mathrm{C}$, apparently, the removal of chemically bound water occurred $[40,48,49]$.
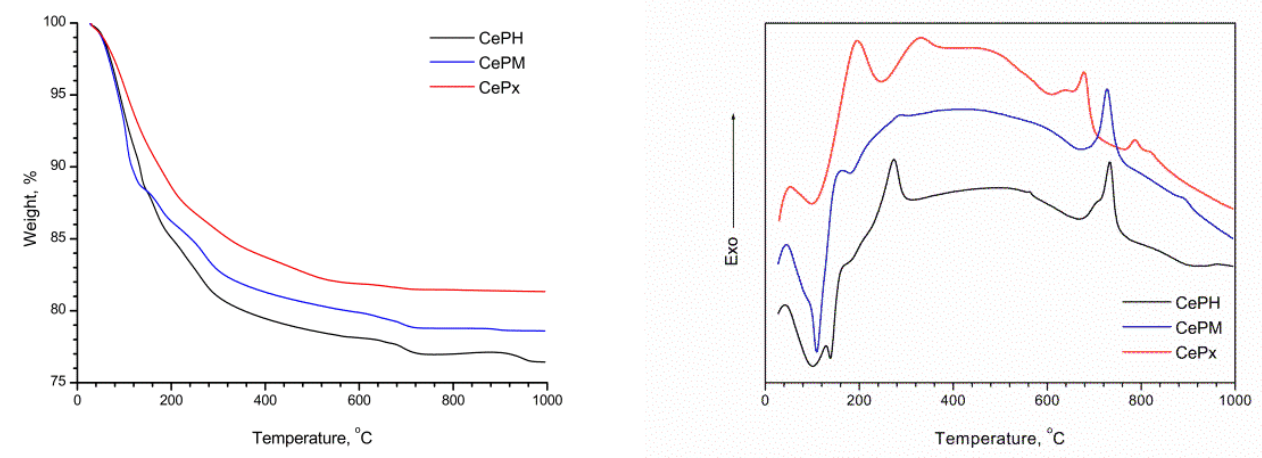

Fig. 3. Thermogravimetric and differential thermal analysis data for ceric hydrogen ophosphate aerogels (CePH, CePM) and xerogel CePx.

At $680-750^{\circ} \mathrm{C}$, a pronounced exothermic effect was observed, accompanied by a small weight loss $(0.5-1 \%)$. This effect has previously been described in the literature [40,50], and is associated with the decomposition of Ce (IV) orthophosphates, with the release of oxygen and the formation of crystalline Ce (III) phosphate. According to XRD data, this led to the formation of monazite phase $\left(\mathrm{CePO}_{4}\right.$, PDF №00-032-199) and cerium tripolyphosphate $\left(\mathrm{CeP}_{3} \mathrm{O}_{9}\right.$, $\mathrm{PDF}$ №00-033-0336). It is noteworthy that the position of this exothermic effect when heating the aerogels (CePM and $\mathrm{CePH})$ shifted to higher temperatures in comparison with the corresponding parameter for xerogel (CePx). Most likely, this difference was due to the differences in chemical composition of the corresponding samples, namely to the higher phosphate to cerium molar ratio in aerogels.

Based on the results of a local EDX analysis (Table 3), the average Ce:P molar ratio was established as being approximately 1:1.5 for CePx xerogel and 1:2 for $\mathrm{CePH}$ and $\mathrm{CePM}$ aerogels. Thus, the chemical composition of CePx xerogel is close to $\mathrm{Ce}_{2} \mathrm{H}_{(}\left(\mathrm{PO}_{4}\right)_{3} \cdot \mathrm{H}_{2} \mathrm{O}$ [51], 
$\mathrm{Ce}_{2}\left(\mathrm{PO}_{4}\right)_{2} \mathrm{HPO}_{4}\left(\mathrm{H}_{2} \mathrm{O}\right)$ [51] and $\mathrm{Ce}\left(\mathrm{PO}_{4}\right)_{1.5}\left(\mathrm{H}_{2} \mathrm{O}\right)\left(\mathrm{H}_{3} \mathrm{O}\right)_{0.5}\left(\mathrm{H}_{2} \mathrm{O}\right)_{0.5}$ [37], while the composition of $\mathrm{CePH}$ and $\mathrm{CePM}$ aerogels is closer to compounds $\mathrm{Ce}\left(\mathrm{HPO}_{4}\right)_{2} \cdot \mathrm{xH}_{2} \mathrm{O}$ [52] and $\mathrm{CeO}\left(\mathrm{H}_{2} \mathrm{PO}_{4}\right)_{2} \cdot 2 \mathrm{H}_{2} \mathrm{O}$ [46]. Fig. 4 provides the survey XPS spectra for CePH and CePM aerogels, as well as for initial nanocrystalline $\mathrm{CeO}_{2}$. In Table 3, the molar ratios of the elements are provided, which were calculated from the integral intensities of the corresponding signals, taking into account the element sensitivity coefficients. The $\mathrm{P} / \mathrm{Ce}$ ratios for aerogels computed from XPS data were in good agreement with the EDX data (Table 3).

Table 3. Ce:P molar ratios in the samples of CePM and CePH aerogels and CePx xerogel, according to EDX and XPS

\begin{tabular}{|c|c|c|c|}
\hline Sample & P:Ce ratio (EDX) & P:Ce ratio (XPS) & $\begin{array}{c}\mathrm{O} /(\mathrm{Ce}+\mathrm{P}) \text { ratio } \\
\text { (XPS) }\end{array}$ \\
\hline $\mathrm{CePx}$ & 1.5 & - & - \\
\hline $\mathrm{CePH}$ & 2.0 & 1.9 & 2.4 \\
\hline $\mathrm{CePM}$ & 2.1 & 2.3 & 2.5 \\
\hline
\end{tabular}

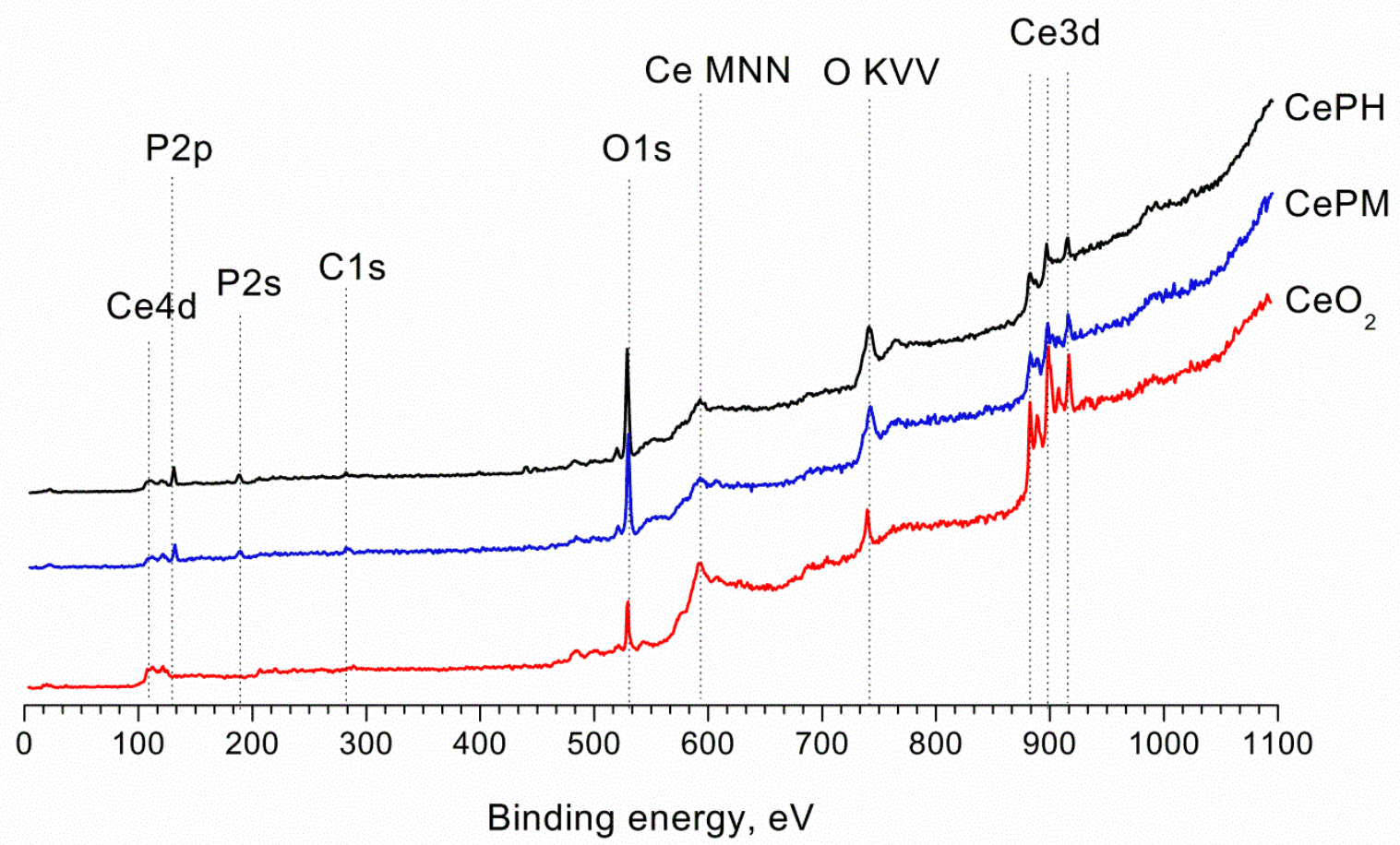

Fig. 4. XPS survey spectra of nano- $\mathrm{CeO}_{2}$ and $\mathrm{CePH}$, CePM aerogels. 
Fig. 5 shows the IR spectra of aerogel and xerogel samples. The general appearance of the IR spectra of $\mathrm{CePx}, \mathrm{CePH}$ and $\mathrm{CePM}$ samples is virtually the same, and is typical for the rare-earth metal phosphates. The absorption maxima at 1,061 (v.str), 980 (br), 620 (str) and 540 (med) $\mathrm{cm}^{-1}$ (see Fig. 5a, b) correspond to the four characteristic symmetric and antisymmetric oscillations of the P-O-bonds in the $\mathrm{PO}_{4}{ }^{3-}$ ion. The absence of the pronounced splitting of the absorption bands of $\mathrm{PO}_{4}$ groups in the IR spectra in the regions of $900-1,200 \mathrm{~cm}^{-1}$ and $600 \mathrm{~cm}^{-1}$ may indicate that the orthophosphate anion in the structure of the obtained substances did not exhibit definite denticity, and could act both as a monodentate, and as a polydentate, ligand. The absorption maxima with the wave numbers 3,225 (str) and 1,628 (str) $\mathrm{cm}^{-1}$ characterise the stretching vibrations of the $\mathrm{OH}$ groups and deformation vibrations of $\mathrm{H}-\mathrm{O}-\mathrm{H}$ in water molecules, respectively. The band at $1,435 \mathrm{~cm}^{-1}$ refers to the valence vibrations of $\mathrm{CO}_{3}{ }^{2-}$, and indicates the presence of a carbonate impurity, (the sample was air-dried). The band at 1,240 $\mathrm{cm}^{-1}$ for the CePM sample can be attributed to the C-O-C oscillations typical of MTBE [53], but, since it was present in the IR spectra of other samples, it is more likely to have been attributed to the $\mathrm{P}-\mathrm{O}-\mathrm{H}$ plane deformation [50].
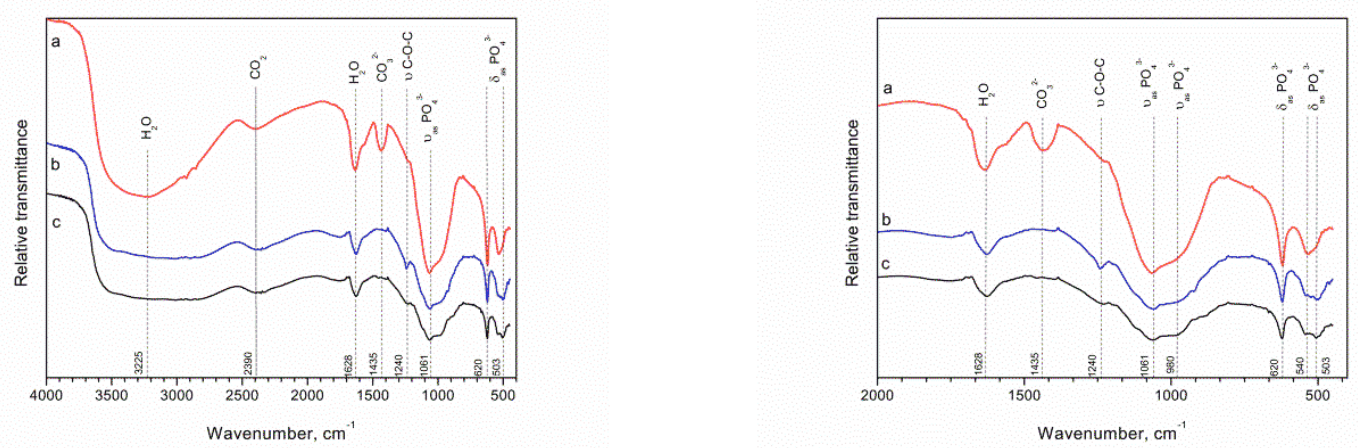

Fig. 5. IR spectra of ceric hydrogen phosphate xerogel CePx (a), and ceric hydrogen phosphate aerogels CePM (b) and CePH (c).

Table 4 shows the specific surface areas of the samples. The relatively low specific surface area $\left(60-70 \mathrm{~m}^{2} / \mathrm{g}\right)$ and high porosity of aerogels $(\sim 99 \%)$ indicate the presence of a large number of macropores in aerogels.

Table 4. Specific surface area of ceric hydrogen orthophosphate aerogel and xerogel samples.

\begin{tabular}{cccc}
\hline Sample & CePx & CePH & CePM \\
\hline $\mathbf{S}_{\mathbf{s p}}, \mathbf{m}^{2} / \mathbf{g}$ & $60 \pm 6$ & $70 \pm 7$ & $75 \pm 8$ \\
\hline
\end{tabular}


Fig. 6 shows the full nitrogen adsorption/desorption isotherm for the CePM aerogel. One can see that the isotherm has a narrow hysteresis, which can be attributed to H3 type according to IUPAC classification [54]. The isotherm reflects the presence of macropores as evidenced by the continuous uptake at the highest relative pressure range. Unfortunately, the method of lowtemperature nitrogen adsorption is not sensitive to pores larger than $\sim 100 \mathrm{~nm}$ [55].

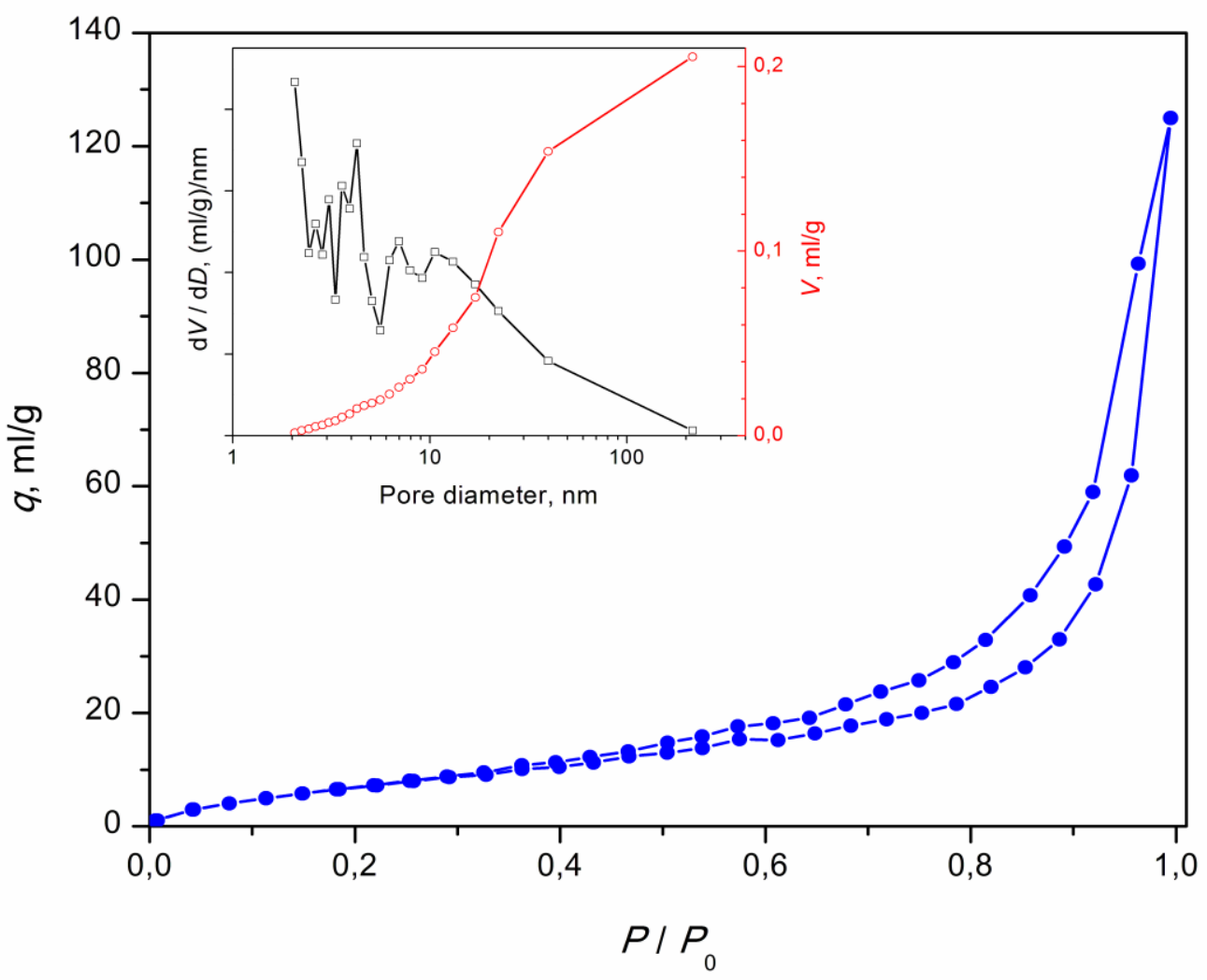

Fig. 6. Nitrogen adsorption/desorption isotherm, pore size distribution and differential pore volume distribution (pore volume density) (in the inset) for the CePM aerogel.

Fig. 7 shows TEM images of CePx, CePH and CePM samples. The results of transmission electron microscopy and electron diffraction indicated that $\mathrm{CePx}, \mathrm{CePH}$ and $\mathrm{CePM}$ samples consisted of fibre-shaped anisotropic particles, at that the smallest fibre thickness (about 15-20 nm) was observed for the CePx sample (Fig. S2). The fibre diameter for the CePH and CePM samples was significantly (approximately 2 times) larger, and, according to the TEM data, they contained inhomogeneities, most probably the closed pores (Figs. S2, 7a, b). 

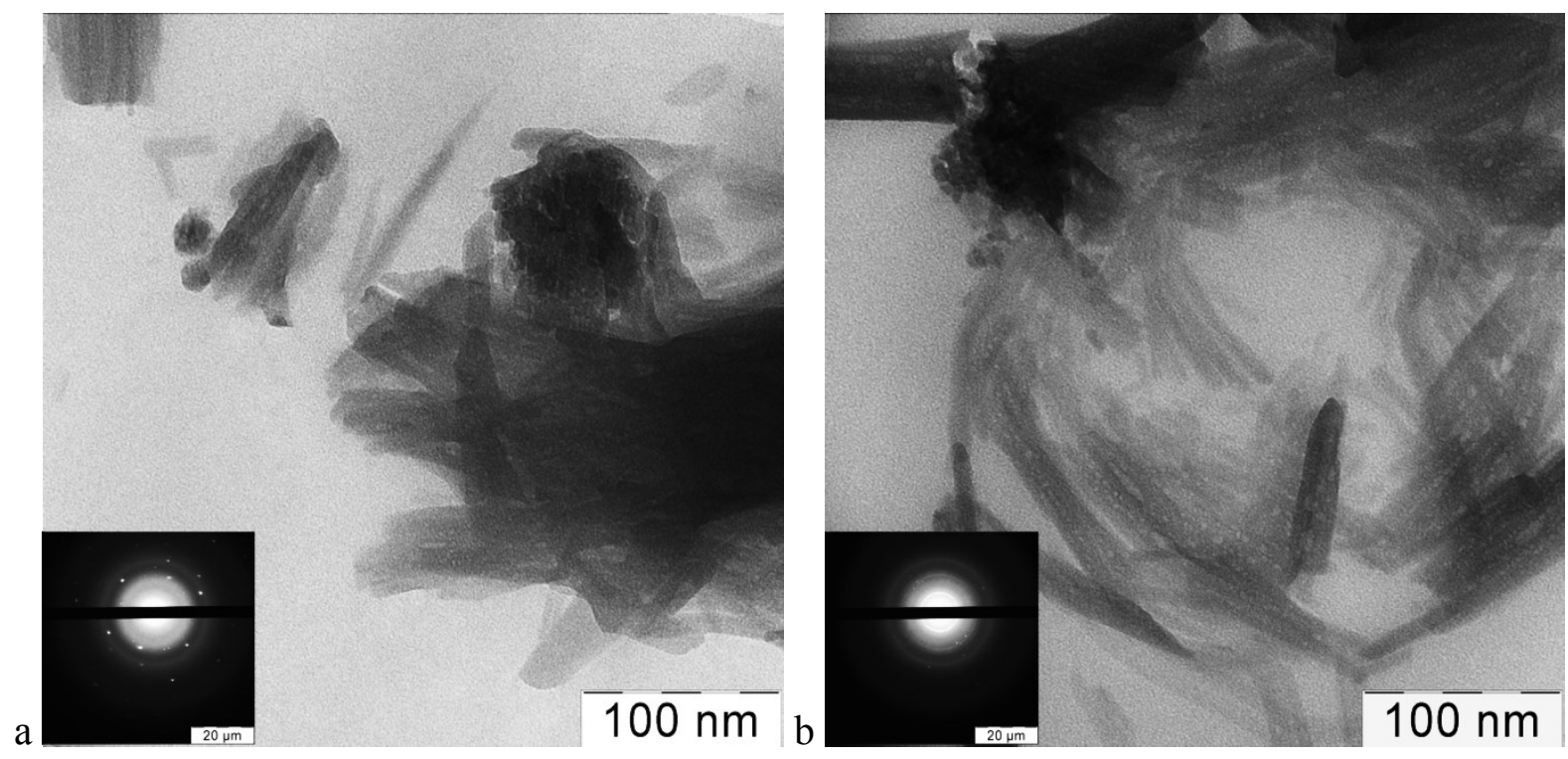

Fig. 7. TEM images of ceric hydrogen phosphate aerogels CePH (a) and CePM (b).

The results of scanning electron microscopy (Fig. 8) were in good agreement with the transmission electron microscopy data, and also indicated that $\mathrm{CePH}$ and $\mathrm{CePM}$ aerogels are characterised by a larger fibre diameter (up to 40-50 nm), compared to CePx xerogel. SEM data also indicated a slight decrease in fibre length (up to 1-2 microns) in aerogels, compared to CePx xerogel (Figs. S3, 8). In addition, the obtained SEM images confirmed the presence of a significant number of macropores in aerogels, with pores from 100 to $500 \mathrm{~nm}$.

a)
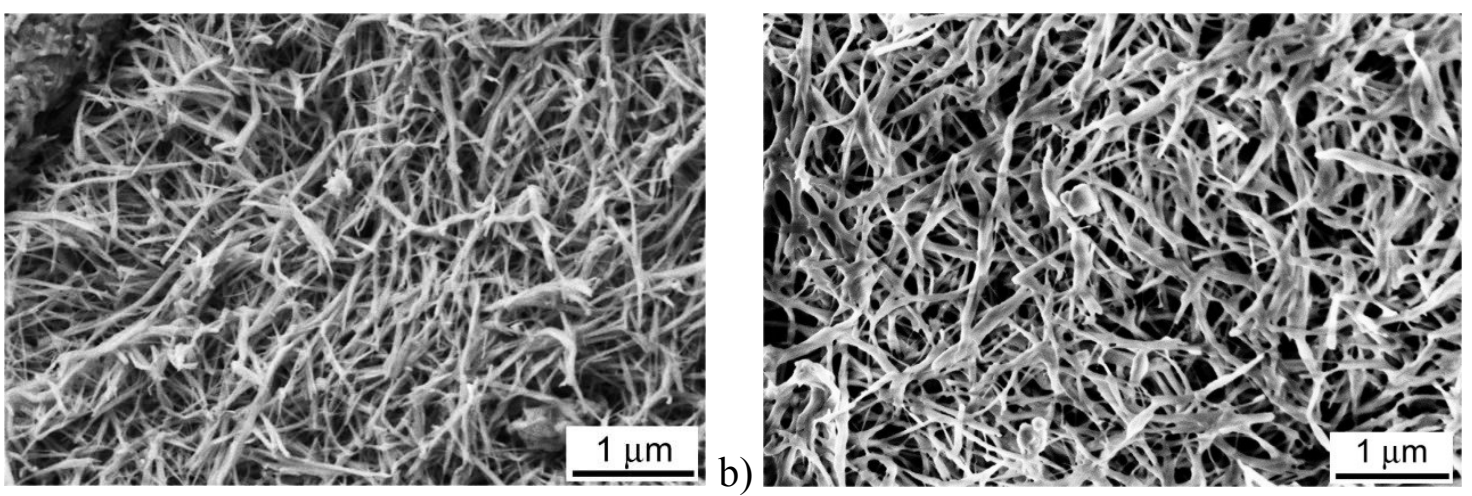

Fig. 8. SEM images of ceric hydrogen phosphate aerogels CePM (a) and CePH (b).

The structure of xerogel (CePx) and aerogel (CePM) samples was independently analysed by means of small angle neutron scattering. Experimental curves of the differential macroscopic neutron cross section $d \Sigma(q) / d \Omega$ versus momentum transfer $q$ (Fig. 9) evidently showed three characteristic $q$-ranges where the behaviours of the SANS cross section $\mathrm{d} \Sigma(q) / \mathrm{d} \Omega$ were significantly different.

In the range $0.02<q<0.15 \AA^{-1}$, the scattering cross section $d \Sigma(q) / d \Omega$ for all the samples satisfied the power law $q^{-n}$. The exponent $n$ values found from the slope of the 
straight-line sections of the experimental curves for $\mathrm{CePx}$ and $\mathrm{CePM}$ samples were equal to $3.32 \pm 0.02$ and $3.96 \pm 0.02$, respectively. The $n$ value for the CePx sample corresponds to the scattering from the fractal surface with the dimension $D_{s}=6-n=2.68 \pm 0.02$. The $n$ value for the aerogel sample was very close to 4, which corresponds to the scattering on inhomogeneities with virtually smooth (in the scale of neutron wavelength used in the experiment, $\lambda=4.9 \AA)$ surfaces $\left(D_{s}=2.04 \pm 0.02\right)$ according to Porod law. Such a difference in fractal properties of xerogel and aerogel samples obtained from the nearly identical starting materials is quite unusual. Probably, surface fractal structure of the xerogel is formed upon dehydration under ambient conditions. Fractalization of smooth materials upon their drying has been observed previously (see e.g. [56]).

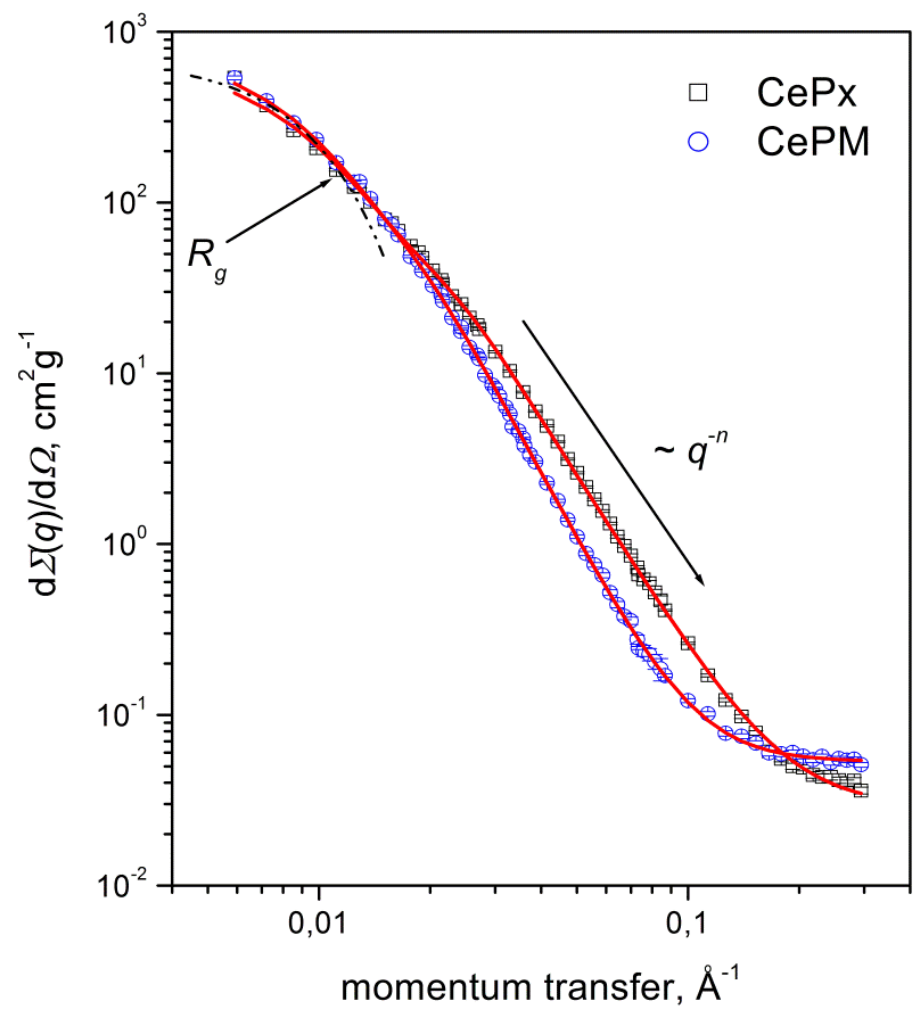

Fig. 9. SANS differential cross section $d \Sigma(q) / d \Omega$ for the samples of ceric hydrogen phosphate xerogel CePx and aerogel CePM. Fitting of experimental data was performed according to [57] and is shown as solid lines.

Deviations from the power law $q^{-n}$ in differential cross section curves $\mathrm{d} \Sigma(q) / \mathrm{d} \Omega$ were observed for all samples, both at small and large $q$-ranges. The deviation in the small $q$-range ( $q$ $<2 \cdot 10^{-2} \AA^{-1}$ ) was due to approaching the Guinier regime [58], where the scattering is governed by the inhomogeneities having the characteristic size $R_{\mathrm{c}}$. Analysis of the scattering in this $q$ range enables an estimation of the $R_{\mathrm{c}}$ value, which is equal to $25.9 \pm 0.6 \mathrm{~nm}$ for $\mathrm{CePx}$, and 
$29.8 \pm 0.7 \mathrm{~nm}$ for CePM samples. These values correspond to the upper estimate of the fibrillae radii in the gels and are in line with TEM and SEM data. In the large $q$-range $\left(q>0.15 \AA^{-1}\right)$, the cross-sections $\mathrm{d} \Sigma(q) / \mathrm{d} \Omega$ became constant, (did not depend on $q$ ), because of incoherent scattering on hydrogen atoms present in the samples in the form of physically and chemically bound water, and scattering on the inhomogeneities having a size comparable to the neutron wavelength used in the experiment.

The combination of the obtained data on the micro- and mesostructure of the obtained aerogels makes it possible to classify them as macroporous materials composed of interlaced fibres. Such macroporous aerogels are typically obtained using specific approaches, such as template synthesis [23], freeze-drying synthesis [59,60] and supercritical drying with rapid removal of supercritical fluid [60]. The macroporous structure is also inherent to aerogels consisting of fibrous or lamellar particles with carbon nanotube-based and cellulose-based aerogels, (which can be referred to as "1D-aerogels"), as well as graphene ("2D aerogels") being classic examples of such materials. It is also reasonable to mention the unusual class of alumina 1D aerogels obtained by the controlled oxidation of metallic aluminum on the surface of aluminum amalgam [61], or the hydrolysis of aluminum trichloride in the presence of propylene oxide [3]. Jung et al. [62] proposed a method for producing monolithic macroporous aerogels using both one-dimensional (nanorods of $\mathrm{Ag}, \mathrm{Si}, \mathrm{MnO}_{2}$ and single-walled nanotubes) and twodimensional nanoparticles $\left(\mathrm{MoS}_{2}, \mathrm{~h}-\mathrm{BN}\right.$ and graphene). The method is based on the selfassembly of the preliminary anisotropic 1D or 2D nanoparticles obtained into a cross-linking network upon the increase in the concentration of their colloidal suspensions. In turn, direct solgel methods for the synthesis of 1D aerogels of complex inorganic compounds are practically unknown. This is because the formation of flexible fibres that could form an interwoven, stable network within a sol-gel process is not typical for such structures. One of the scarce examples of sol-gel derived $1 \mathrm{D}$ aerogels is vanadium pentoxide gels derived from neutral $\mathrm{VO}(\mathrm{OH})_{3}$ species or vanadium alkoxide precursors [63]. These gels form according to polymeric growth mechanism which can be judged as one of the possible mechanisms for cerium phosphate fibrillae formation, too. The formation of gels from poorly soluble complex inorganic compounds, in particular orthophosphates of transition and rare-earth elements, is also complicated, because of their low solubility in the liquid phase, which leads to their hasty precipitation in the form of fine precipitates, hindering the structuration to impart the desirable morphology. 


\section{Conclusions}

Monolithic aerogels based on ceric hydrogen orthophosphates, being the first representatives of the 1D rare-earth phosphate aerogel family, have been obtained and characterised. It has been shown that these gels have a specific surface of $60-70 \mathrm{~m}^{2} / \mathrm{g}$ and, in addition, have a high porosity ( $\sim 99 \%)$, due to the presence of pores with a wide range of sizes, including macropores. The obtained aerogels had a fibrous structure, with a fibre thickness up to $\sim 50 \mathrm{~nm}$ and a length of 1-2 $\mu \mathrm{m}$, which allows considering them as a new type of 1D aerogel based on complex inorganic compounds.

\section{Acknowledgements}

We are grateful to Dr. O.V. Boytsova and Dr. N.P. Simonenko for their kind assistance. The effect of the supercritical fluid on the aerogels' structure and composition was conducted with the support of the Russian Science Foundation (14-13-01150). This research was performed using the equipment of the JRC PMR IGIC RAS.

\section{References}

1. Compendium of Chemical Terminology, 2nd ed. (the "Gold Book"). Eds. edited by A. D. McNaught, A. Wilkinson. Blackwell Scientific Publications, Oxford. 1997.

2. A.C. Pierre, G.M. Pajonk. Chemistry of aerogels and their applications // Chem. Rev., 2002, 102, 4243-4266.

3. T.F. Baumann, A.E. Gash, S.C. Chinn, A.M. Sawvel, R.S. Maxwell, J.H. Satcher. Synthesis of high-surface-area alumina aerogels without the use of alkoxide precursors // Chem. Mater., 2005, 17, 395-401.

4. A.E. Gash, J.H. Satcher, R.L. Simpson. Strong akaganeite aerogel monoliths using epoxides: synthesis and characterization // Chem. Mater., 2003, 15, 3268-3275.

5. T.F. Baumann, S. O. Kucheyev, A. E. Gash, J.H. Satcher. Facile synthesis of a crystalline, high-surface-area $\mathrm{SnO}_{2}$ aerogel // Adv. Mater., 2005, 17, 1546-1548.

6. A.E. Gash, J.H. Satcher, R.L. Simpson. Monolithic nickel (II)-based aerogels using an organic epoxide: the importance of the counterion // J. Non-Cryst. Solids, 2004, 350, 145-151.

7. S.A. Lermontov, E.A. Straumal, A.A. Mazilkin, I.I. Zverkova, A.E. Baranchikov, B.B. Straumal, V. K. Ivanov. How to tune the alumina aerogels structure by the variation of a supercritical solvent. Evolution of the structure during heat treatment // J. Phys. Chem. C, 2016, 120, 3319-3325. 
8. S. Ganguly, C. Zhou, D. Morelli, J. Sakamoto, S.L. Brock. Synthesis and characterization of telluride aerogels: effect of gelation on thermoelectric performance of $\mathrm{Bi}_{2} \mathrm{Te}_{3}$ and $\mathrm{Bi}_{2-\mathrm{x}} \mathrm{Sb}_{\mathrm{x}} \mathrm{Te}_{3}$ nanostructures // J. Phys. Chem. C, 2012, 116, 17431-17439.

9. S. Ghosal, J.C. Hemminger, H. Bluhm, B.S. Mun, E.L.D. Hebenstreit, G. Ketteler, D.F. Ogletree, F.G. Requejo, M. Salmeron. Electron spectroscopy of aqueous solution interfaces reveals surface enhancement of halides // Science, 2005, 307, 563-566.

10. S. Bag, P.N. Trikalitis, P.J. Chupas, G.S. Armatas, M.G. Kanatzidis. Porous semiconducting gels and aerogels from chalcogenide clusters // Science, 2007, 317, 490-493.

11. N. Leventis, A. Sadekar, N. Chandrasekaran, C. Sotiriou-Leventis. Click synthesis of monolithic silicon carbide aerogels from polyacrylonitrile-coated 3D silica networks // Chem. Mater., 2010, 22, 2790-2803.

12. T. Horikawa, J. Hayashi, K. Muroyama. Size control and characterization of spherical carbon aerogel particles from resorcinol-formaldehyde resin // Carbon, 2004, 42, 169-175.

13. M.A. Worsley, P.J. Pauzauskie, T.Y. Olson, J. Biener, J.H. Satcher, T.F. Baumann. Synthesis of graphene aerogel with high electrical conductivity // J. Amer. Chem. Soc., 2010, $132,14067-14069$.

14. M.A. Worsley, J.H. Satcher, T.F. Baumann. Synthesis and characterization of monolithic carbon aerogel nanocomposites containing double-walled carbon nanotubes // Langmuir, 2008, 24, 9763-9766.

15. M.D. Marco, F. Markoulidis, R. Menzel, S.M. Bawaked, M. Mokhtar, S.A. Al-Thabaiti, S.N. Basahel, M.S.P. Shaffer. Cross-linked single-walled carbon nanotube aerogel electrodes via reductive coupling chemistry // J. Mater. Chem. A, 2016, 4, 5385-5389.

16. L. Dong, Q. Yang, C. Xu, Y. Li, D. Yang, F. Hou, H. Yin, F. Kang. Facile preparation of carbon nanotube aerogels with controlled hierarchical microstructures and versatile performance // Carbon, 2015, 90, 164-171.

17. S.M. Jones. A method for producing gradient density aerogel // J. Sol-Gel Sci. Technol., $2007,44,255-258$.

18. D.W. Schaefer, K.D. Keefer. Structure of random porous materials: Silica Aerogel // Phys. Rev. Letters, 1986, 56, 2199-2202.

19. L. Liang, Y. Xu, Y. Lei, H. Liu. 1-Dimensional $\mathrm{AgVO}_{3}$ nanowires hybrid with 2dimensional graphene nanosheets to create 3-dimensional composite aerogels and their improved electrochemical properties // Nanoscale, 2014, 6, 3536-3539.

20. M.B. Bryning, D.E. Milkie, M.F. Islam, L.A. Hough, J.M. Kikkawa, A.G. Yodh. Carbon Nanotube Aerogels // Adv. Mater., 2007, 19, 661-664. 
21. P. Hao, J. Tian, Y. Sang, C.-C. Tuan, G. Cui, X. Shi, C.P. Wong, B. Tang, H. Liu. 1D NiCo oxide and sulfide nanoarray/carbon aerogel hybrid nanostructures for asymmetric supercapacitors with high energy density and excellent cycle stability // Nanoscale, 2016, 8, 16292-16301.

22. S. Nardecchia, D. Carriazo, M.L. Ferrer, M.C. Gutiérrez, F. Monte. Three dimensional macroporous architectures and aerogels built of carbon nanotubes and/or graphene: synthesis and applications // Chem. Soc. Rev., 2013, 42, 794-830.

23. Y. Zhu, T. Shimizu, T. Kitajima, K. Morisato, N. Moitra, N. Brun, T. Kiyomura, K. Kanamori, K. Takeda, H. Kurata, M. Tafu, K. Nakanishi. Synthesis of robust hierarchically porous zirconium phosphate monolith for efficient ion adsorption // New J. Chem., 2015, 39, 2444-2450.

24. P.A. Iacobucci. Inorganic phosphate aerogels and their preparation. U.S. Patent No. 4,622,310. Washington, DC: U.S. Patent and Trademark Office. 1986.

25. R.A. Boyse, E. I. Ko. Preparation and characterization of zirconia-phosphate aerogels // Catal. Lett., 1996, 38, 225-230.

26. A. Waghray, E.I. Ko. One-step synthesis and characterization of niobia-phosphate aerogels // Catal. Today, 1996, 28, 41-47.

27. S.L. Lee, H. Nur, H. Hamdan. Physical properties and bifunctional catalytic performance of phosphate-vanadium impregnated silica-titania aerogel // Catal. Lett., 2009, 132, 28-33.

28. V. Sydorchuk, V. Zazhigalov, S. Khalameida, E. Diyuk, J. Skubiszewska-Zięba, R. Leboda, L. Kuznetsova. Solvothermal synthesis of vanadium phosphates in the form of xerogels, aerogels and mesostructures // Mater. Res. Bull., 2010, 45, 1096-1105.

29. S.S. Metwally, B. El-Gammal, H.F. Aly, S.A. Abo-El-Enein. Removal and separation of some radionuclides by poly-acrylamide based $\mathrm{Ce}(\mathrm{IV})$ phosphate from radioactive waste solutions // Sep. Sci. Technol., 2011, 46, 1808-1821.

30. E.M. Larsen, W.A. Cilley. The exchange of $\mathrm{Li}^{+}, \mathrm{Na}^{+}$and $\mathrm{K}^{+}$on cerium (IV) phosphate // J. Inorg. Nucl. Chem., 1968, 30, 287-293.

31. P. Barboux, R. Morineau, J. Livage. Protonic conductivity in hydrates // Solid State Ionics, 1988, 27, 221-225.

32. G.M.S.R.O. Rocha, R.A.W. Johnstone, M.G.P.M.S. Neves. Catalytic effects of metal (IV) phosphates on the oxidation of phenol and 2-naphthol // J. Mol. Catal. A, 2002, 187, 95104.

33. C.-H. Yan., Z.-G. Yan., Y.-P. Du., J. Shen., C. Chang., W. Feng. Controlled synthesis and properties of rare earth nanomaterials // Handbook on the Physics and Chemistry of rare earths. 2011, 41, 275-472. 
34. S.N. Achary, S. Bevara, A.K. Tyagi. Recent progress on synthesis and structural aspects of rare-earth phosphates // Coordin. Chem. Rev., 2017, 40, 266-297.

35. N. Clavier, R. Podor, N. Dacheux. Crystal chemistry of the monazite structure // J. Eur. Ceram. Soc., 2011, 31, P. 941-976.

36. M. Nazaraly, G. Wallez, C. Chaneac, E. Tronc, F. Ribot, M. Quarton, J.-P. Jolivet. The first structure of a cerium (IV) phosphate: ab initio Rietveld analysis of $\mathrm{Ce}^{\mathrm{IV}}\left(\mathrm{PO}_{4}\right)\left(\mathrm{HPO}_{4}\right)_{0.5}\left(\mathrm{H}_{2} \mathrm{O}\right)_{0.5} / /$ Angew. Chem. Int. Ed., 2005, 44, 5691-5694.

37. M. Nazaraly, C. Chaneac, F. Ribot, G. Wallez, M. Quarton, J.-P. Jolivet. A new story in the structural chemistry of cerium (IV) phosphate // J. Phys. Chem. Solids, 2007, 68, 795-798.

38. M. Nazaraly, M. Quarton, G. Wallez, C. Chaneac, F. Ribot, J.-P. Jolivet. $\mathrm{Ce}\left(\mathrm{H}_{2} \mathrm{O}\right)\left(\mathrm{PO}_{4}\right)_{3 / 2}\left(\mathrm{H}_{3} \mathrm{O}\right)_{1 / 2}\left(\mathrm{H}_{2} \mathrm{O}\right)_{1 / 2}$, a second entry in the structural chemistry of cerium (IV) phosphate // Solid State Sci., 2007, 9, 672-677.

39. W.N. Hartley. Contributions to the chemistry of cerium compounds // J. Chem. Soc., 1882, 41, 202-209.

40. T.O. Shekunova, A.E. Baranchikov, O.S. Ivanova, L.S. Skogareva, N.P. Simonenko, Yu.A. Karavanova, V.A. Lebedev, L.P. Borilo, V.K. Ivanov. Cerous phosphate gels: synthesis, thermal decomposition and hydrothermal crystallization paths // J. Non-Cryst. Solids, 2016, 447, 183-189.

41. V.K. Ivanov, A.E. Baranchikov, O.S. Polezhaeva, G.P. Kopitsa, Yu.D. Tret'yakov. Oxygen nonstoichiometry of nanocrystalline ceria // Russ. J. Inorg. Chem., 2010, 55, 325-327.

42. Kh.E. Yorov, N.A. Sipyagina, A.N. Malkova, A.E. Baranchikov, S.A. Lermontov, L.P. Borilo, V.K. Ivanov. Methyl tert-butyl ether as a new solvent for the preparation of $\mathrm{SiO}_{2}-\mathrm{TiO}_{2}$ binary aerogels // Inorg. Mater., 2016, 52, 163-169.

43. U. Keiderling. The new 'BerSANS-PC' software for reduction and treatment of small angle neutron scattering data // Appl. Phys. A, 2002, 74, 1455-1457.

44. C. Daniel, S. Longo, R. Ricciardi, E. Reverchon, G. Guerra. Monolithic nanoporous crystalline aerogel // Macromol. Rapid Commun., 2013, 34, 1194-1207.

45. H. Hayashi, T. Ebina, Y. Onodera, T. Iwasaki. Strontium immobilization by fibrous cerium(IV) bis(monohydrogenphosphate) under hydrothermal conditions // Bull. Chem. Soc. Jpn., 1997, 70, 1701-1708.

46. H. Hayashi, K. Torii, S. Nakata. Hydrothermal treatment and strontium ion sorption properties of fibrous cerium (IV) hydrogenphosphate // J. Mater. Chem., 1997, 7, 557-562.

47. K.F. Chen, C.M. Kao, L.C. Wu, R.Y. Surampalli, S.H. Liang. Methyl Tert-Butyl Ether (MTBE) Degradation by Ferrous Ion-Activated Persulfate Oxidation: Feasibility and Kinetics Studies // Water Environ. Res., 2009, 81, 687-694. 
48. H. Hirai, T. Masui, N. Imanaka, G. Adachi. Characterization and thermal behavior of amorphous rare earth phosphates // J. Alloys Compd., 2004, 374, 84-88.

49. T. Masui, H. Hirai, N. Imanaka, G. Adachi. Characterization and thermal behavior of amorphous cerium phosphate // Phys. Stat. Sol. A, 2003, 198, 364-368.

50. M. Nazaraly, G. Wallez, C. Chane, E. Tronc, F. Ribot, M. Quarton, J.-P. Jolivet. Synthesis and characterization of $\mathrm{Ce}^{\mathrm{IV}}\left(\mathrm{PO}_{4}\right)\left(\mathrm{HPO}_{4}\right)_{0.5}\left(\mathrm{H}_{2} \mathrm{O}\right)_{0.5} / /$ J. Phys. Chem. Solids, 2006, 67, 1075-1078.

51. V. Brandel, N. Clavier, N. Dacheux. Synthesis and characterization of uranium (IV) phosphate-hydrogenphosphate hydrate and cerium (IV) phosphate-hydrogenphosphate hydrate // J. Solid State Chem., 2005, 178, 1054-1063.

52. R.G. Herman, A. Clearfield. Crystalline cerium (IV) phosphates - I. Preparation and characterization of crystalline compounds // J. Inorg. Nucl. Chem., 1975, 37, 1697-1704.

53. G. Socrates. Infrared and Raman Characteristic Group Frequencies: Tables and Charts. J. Willey \& Sons. 2004. 366 p.

54. M. Thommes, K. Kaneko, A.V. Neimark, J.P. Olivier, F. Rodriguez-Reinoso, J. Rouquerol, K.S.W. Sing. Physisorption of gases, with special reference to the evaluation of surface area and pore size distribution (IUPAC Technical Report) // Pure Appl. Chem., 2015, 87, 1051-1069.

55. L.M. Anovitz, D.R. Cole. Characterization and analysis of porosity and pore structures // Rev. Mineral. Geochem., 2015, 80, 61-164.

56. S. Lee, T.B. Fischer, M.R. Stokes, R.J. Klingler, J. Ilavsky, D.K. McCarty, M.O. Wigand, A. Derkowski, R.E. Winans. Dehydration Effect on the Pore Size, Porosity, and Fractal Parameters of Shale Rocks: Ultrasmall-Angle X-ray Scattering Study // Energy Fuels, 2014, 28, 6772-6779.

57. G. Beaucage, D.W. Schaefer. Structural studies of complex systems using small-angle scattering: a unified Guinier/power-law approach // J. Non-Cryst. Solids, 1994, 172, 797-805.

58. A. Guinier. A diffraction des rayons $\mathrm{X}$ aux très petits angles: application à l'étude de phénomènes ultramicroscopiques // Ann. Phys., 1939, 12, 161-237.

59. S.M. Jung, D.L. Mafra, C.-T. Lin, H.Y. Jung, J. Kong. Controlled porous structures of graphene aerogels and their effect on supercapacitor performance // Nanoscale, 2015, 7, 43864393.

60. K. Ganesan, A. Dennstedt, A. Barowski, L. Ratke. Design of aerogels, cryogels and xerogels of cellulose with hierarchical porous structures // Mater. Design, 2016, 92, 345-355. 
61. A.N. Khodan, G.P. Kopitsa, Kh.E. Yorov, A.E. Baranchikov, V.K. Ivanov, A. Feoktystov, V. Pipich. Structure of aluminium oxohydroxide aerogels: small angle scattering studies // J. Surf. Invest., 2017, 11 (in press).

62. S.M. Jung, H.Y. Jung, M.S. Dresselhaus, Y.J. Jung, J. Kong. A facile route for 3D aerogels from nanostructured 1D and 2D materials // Sci. Rep., 2012, 2, 849.

63. J. Livage. Vanadium pentoxide gels // Chem. Mater., 1991, 3, 578-593. 


\section{Supplementary material}

\section{First rare-earth phosphate aerogel: sol-gel synthesis of monolithic ceric hydrogen}

phosphate aerogel

Yorov K.E. ${ }^{1}$, Shekunova T.O. ${ }^{1,2}$, Baranchikov A.E. ${ }^{1,2}$, Kopitsa G.P. ${ }^{3,4}$, Almásy L. ${ }^{5}$, Skogareva L.S. ${ }^{2}$, Kozik V.V. ${ }^{6}$, Malkova A.N. ${ }^{7}$, Lermontov S.A. ${ }^{7}$, Ivanov V.K. ${ }^{2,8 *}$

${ }^{1}$ Lomonosov Moscow State University

${ }^{2}$ Kurnakov Institute of General and Inorganic Chemistry of the Russian Academy of Sciences

3 Petersburg Nuclear Physics Institute of National Research Centre "Kurchatov Institute"

${ }^{4}$ Grebenshchikov Institute of Silicate Chemistry of the Russian Academy of Sciences

${ }^{5}$ Institute for Solid State Physics and Optics, Wigner Research Centre for Physics, Hungarian Academy of Sciences

${ }^{6}$ National Research Tomsk State University

${ }^{7}$ Institute of Physiologically Active Compounds of the Russian Academy of Sciences

${ }^{8}$ Lomonosov Moscow State University of Fine Chemical Technologies

*van@igic.ras.ru

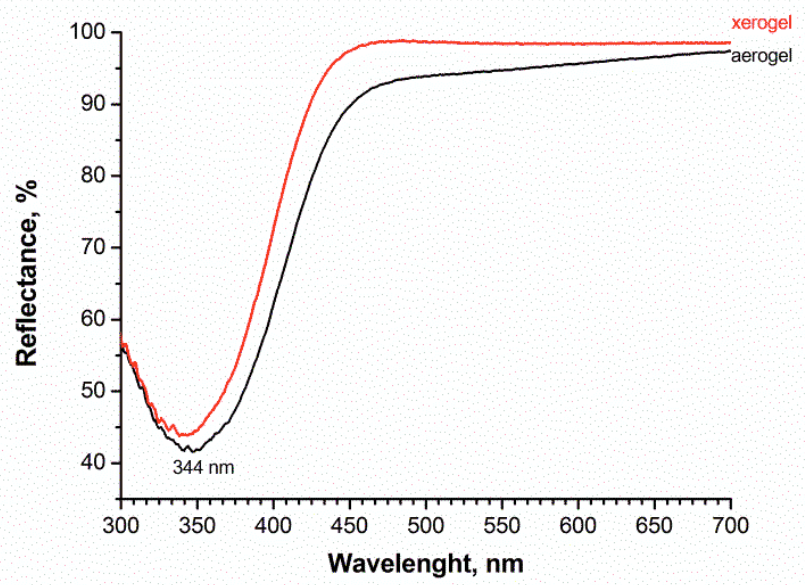

Fig. S1. Diffuse UV-vis reflectance spectra of CePx (xerogel) and CePH (aerogel) samples. 


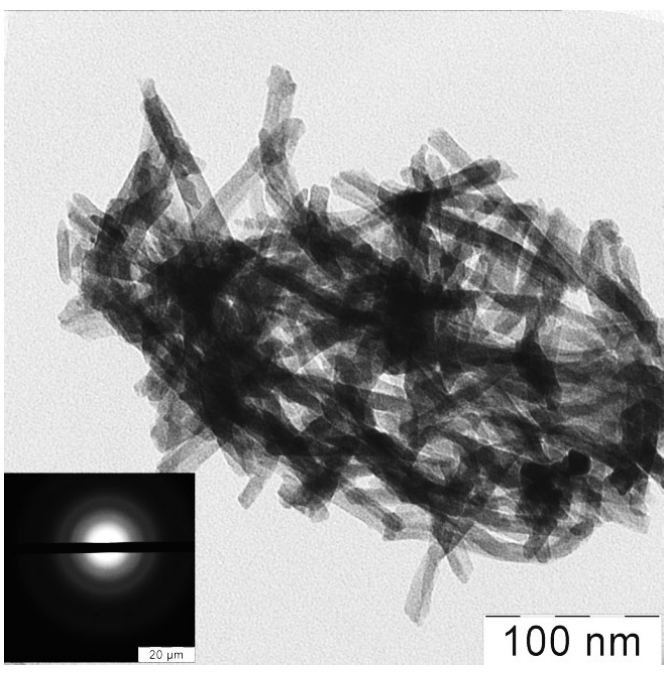

Fig. S2. TEM images of ceric hydrogen phosphate xerogel CePx.

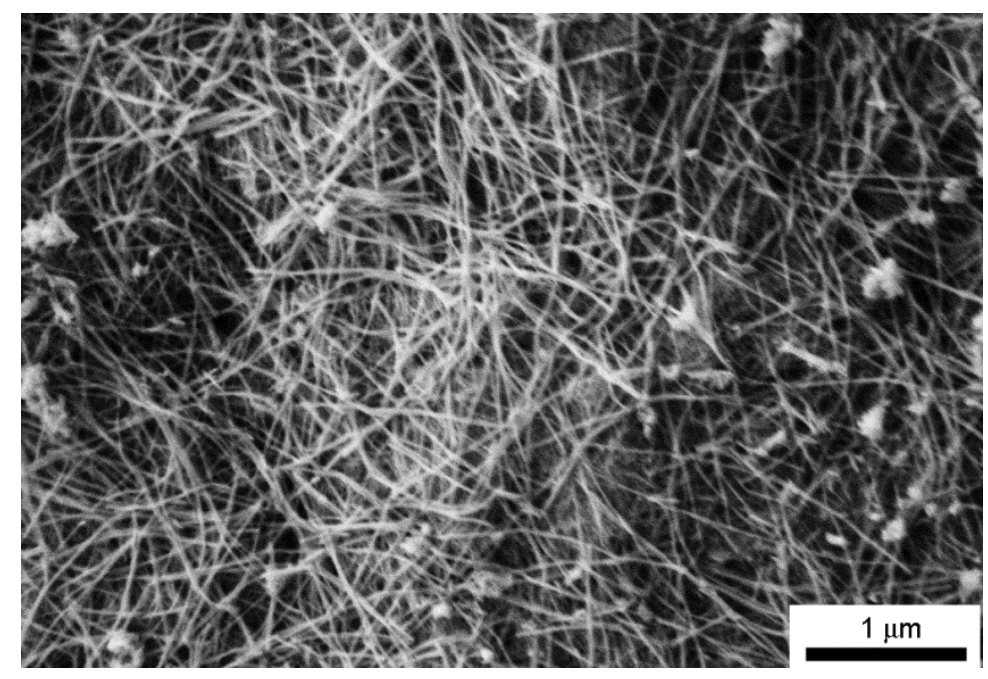

Fig. S3. SEM images of ceric hydrogen phosphate xerogel CePx. 